\title{
Smart Oncolytic Adenovirotherapy to Induce Killing of Cancer Cells and Elicit Antitumor
}

\section{Immunity}

\author{
Received: 20 October 2020 \\ Accepted: 28 September 2021 \\ Published: 24 January 2022
}

\author{
Laura O. Enekegho ${ }^{1 *}$ and David T. Stuart ${ }^{1}$ \\ ${ }^{1}$ Department of Biochemistry, University of Alberta \\ * Corresponding author: enekegho@ualberta.ca
}

\begin{abstract}
Cancer is one of the leading causes of death in the world and accounts for over $30 \%$ of deaths in Canada. Chemotherapy and radiotherapeutic approaches are currently used in practice to treat cancerous growths. Virotherapy is an emerging treatment that uses biotechnology to convert viruses into therapeutic agents to treat specific types of cancer. This process reprograms viruses to become oncolytic and target tumor cells for lysis. It also uses these viruses to recruit inflammatory and vaccination responses by the immune system to help kill surrounding tumor cells while also establishing immunological memory to help against metastasis and future recurrence. Adenoviruses are a group of viruses that infect humans, causing fever and minor respiratory illness. They have been employed as oncolytic agents and have demonstrated potential for eliciting inflammatory responses from the immune system to kill cancer cells and induce antitumor immunity. Advances in virotherapy strategy have progressed toward overcoming tumor-mediated immunosuppression, which allows cancerous cells to evade the immune system and escape cell destruction, especially when combined with other therapeutic treatments. This review focuses on the mechanism by which engineered adenoviruses can stimulate the immune system for cell killing and elicit antitumor immunity and further discusses current limitations of the strategy and improvements to increase the overall efficacy of this cancer treatment.
\end{abstract}

KEY WORDS: cancer, virotherapy, adenoviruses, immune system, antitumor immunity, cancer killing, cell lysis

\section{1 | INTRODUCTION}

\section{Scope of Cancer}

Cancer is a group of diseases resulting from gene mutations in normal cells. The mutations give specific traits or hallmarks to cancer cells that allow them to grow and divide indefinitely in an unregulated fashion and to evade programmed cell death (Tian et al., 2011). Cancer is one of the leading causes of death in the world, accounting for over $30 \%$ of all deaths in Canada alone (Siegel et al., 2015). Various cancer treatments are currently in practice, such as chemotherapy, radiation therapy, and immunotherapy, to help combat and treat cancerous growths and promote cancer remission (Pandha, 2016). Virotherapy is an emerging treatment that uses biotechnology to convert viruses into therapeutic agents to treat specific types of cancer. This process reprograms viruses to become oncolytic and target tumor cells for lysis (Goradel et al., 2019). It also uses these viruses to recruit inflammatory and vaccination responses by the immune system to help kill surrounding tumor cells while also establishing a long immunological memory to help against later infections (Dias et al., 2012).

\section{Virotherapy}

Virotherapy makes use of oncolytic viruses which selectively infect and destroy cancer cells but not normal cells (Moaven et al., 2021). Oncolytic viruses are modified or attenuated replication-competent viruses that cause cancer cell lysis from selective and specific replication and activate systemic immune system responses, which help to destroy the remaining tumor and other cancerous cells (Goradel et al., 2019). Oncolytic viruses have the potential to induce 
vaccination processes to elicit antitumor immunity to protect the body against the reappearance or further growth of that specific tumor type (Huang et al., 2019). A variety of different oncolytic viruses have been engineered and attenuated, namely the Herpes Simplex virus (HSV), vaccinia virus, myxoma virus, measles, reovirus, vesicular stomatitis virus (VSV), Semliki Forest virus (SFV) and the adenovirus (Ramachandran et al., 2017, Huang et al., 2019, Chen et al., 2021, Kangas et al., 2021, Lou et al., 2021, Oosenbrug et al., 2021, Panagioti et al., 2021, Woo et al., 2021). Oncolytic viruses are typically administered in conjunction with chemotherapy and radiation treatments to specifically identify and kill cancer cells (Malogolovkin et al., 2021).

Oncolytic viruses have proven potential for cancer treatment by inducing direct lysis of cancerous cells as well as inducing immune cell responses that are directed toward tumor cell antigens (Goradel et al., 2019). A key issue with many virotherapy practices is ensuring and optimizing the stimulation of the immune system to selectively kill cancer cells. Genetically engineering viral gene expression allows for the potentiation of viruses as a tool for generating antitumor host immune responses (Kellish et al., 2019). This complex genetic expression can be achieved by using genetic circuits (Kim et al., 2018). Genetic circuits are an assembly of transgenes, referred to as biological parts, and encoding proteins or in some cases untranslated RNA that allows specific input signals to be detected and interpreted to control the expression of an output RNA or protein (Wang, Xue, et al., 2021). The circuit constructed may be simple or complex, but the goal is to engineer a virus that can detect whether it has infected a normal cell or a tumor cell and subsequently respond by replicating in and killing tumor cells while not replicating in normal cells (Tripodi et al., 2021). To understand this process, this review will provide some background on several smart microbial engineering techniques that improve the specificity of oncolytic adenoviruses in recognizing tumor cells and increase the overall efficacy of immune system responses towards cancer cells.

\section{Adenoviruses}

Oncolytic adenoviruses are non-enveloped viruses with a double-stranded linear DNA genome of about 36 kilobase pairs enclosed by a protein capsid (Russell, 2009). Its genome consists of early genes (E1, E2, and E7), which are important in the early stages of viral replication, and late genes (L1, L2, L3, L4, and L5) that encode structural proteins that make up the viral capsid (Russell, 2009, Gallardo et al., 2021). Adenoviruses gain entry to the host cell via attachment to one of several possible plasma membrane receptors including
MHC class I molecules and the coxsackie-adenovirus receptor (CAR), followed by endocytosis of the virus into the cell (Bergelson et al., 1997). Following uncoating and entry into the host cell nucleus, the virus then hijacks the host cell transcription machinery to transcribe the immediate-early gene E1, which encodes the E1A protein (Wold \& Horowitz, 2007). The expression of the E1A protein triggers expression of the other early viral genes and leads to the activation of viral replication. E1A achieves its function largely through binding to the cellular tumor suppressor retinoblastoma protein $(\mathrm{Rb})$, which normally acts as a repressor to the cellular transcription factor E2F. When viral E1A binds to and inactivates Rb, this frees E2F from repression and the active E2F proceeds to induce transcription of cellular genes and the viral early genes that lead to viral replication and cell lysis (Berk, 2005).

The first versions of oncolytic adenovirus vectors made use of viruses defective in E1A function (Heise et al., 2000). Lacking E1A, these viruses were unable to inactivate $\mathrm{Rb}$ and free E2F. Without E2F, the mutant virus could not replicate, thus normal cells were unharmed (Heise \& Kirn, 2000). In contrast, many cancer cells are mutated in $\mathrm{Rb}$, which allows them to freely grow and divide. When such cancerous cells are infected with an E1A defective virus, the virus is unrestrained and rapidly replicates, lysing the tumor cells (Russell et al., 2012).

Adenoviruses are a very suitable tool for virotherapy because they do not integrate into the host cell genome, have very low pathogenic risk to normal cells, high genomic stability, relatively large genomic capacity, and wide range of tissue tropism (Huang et al., 2019, Tripodi et al., 2021). Despite this, genetic engineering is still required to increase the specificity and reduce the pathogenicity of the virus to ensure its safety in clinical environments. Smart oncolytic engineering also allows for the encoding of immune system modulators that can promote anti-cancer cytotoxicity of the oncolytic virus (Huang et al., 2019).

Oncolytic adenovirus can infect a wide range of cell types, but a combination of cellular checkpoint controls including $\mathrm{Rb}$ and $\mathrm{p} 53$ prevent viral replication in normal cells (Huang et al. 2019). In contrast, proliferating checkpoint defective cancer cells allow viral replication, leading to virus mediated lysis of the tumor cells (Fig. 1). This not only kills the infected tumor cells but releases tumor cell antigens, potentially allowing recognition by the host immune system that can be synergised with the oncolytic virus to trigger immune-mediated killing of uninfected tumor cells. This can also generate immunity that will allow the immune system to recognize tumors that develop later (Huang et al., 2016). 


\section{Smart Oncolytic Genetic Circuits}

The inherent ability of cytolytic adenoviruses to kill tumor cells can be substantially enhanced through genetic engineering and synthetic biology approaches. Reprogramming adenoviruses to allow the immune system to recognize tumor cells involves significant engineering of the viral chromosome. The architecture of smart microbial oncolytic engineering usually follows the construction of genes that will encode three subsystems: a biosensor, a transducer or processing subsystem, and an actuator or output that are assembled and engineered into the virus (Fig. 2). The first is the sensing subsystem, which includes a wide range of protein or/and nucleic nucleic-acid biosensors (Fig. 3). These biosensors could be transcription factors, riboswitches, which are regulatory subunits of control mRNA, tumor cell specific promoters, or even a combination of these (Kim et al., 2018, Gao et al., 2019). The biosensor module responds to specific signals in the cell allowing differentiation between normal and tumor cells, and relays messages that allow for viral replication and immune response specifically against cancerous cells.

The next subsystem is the processing subsystem, or the transducer, which interprets the message from the sensing

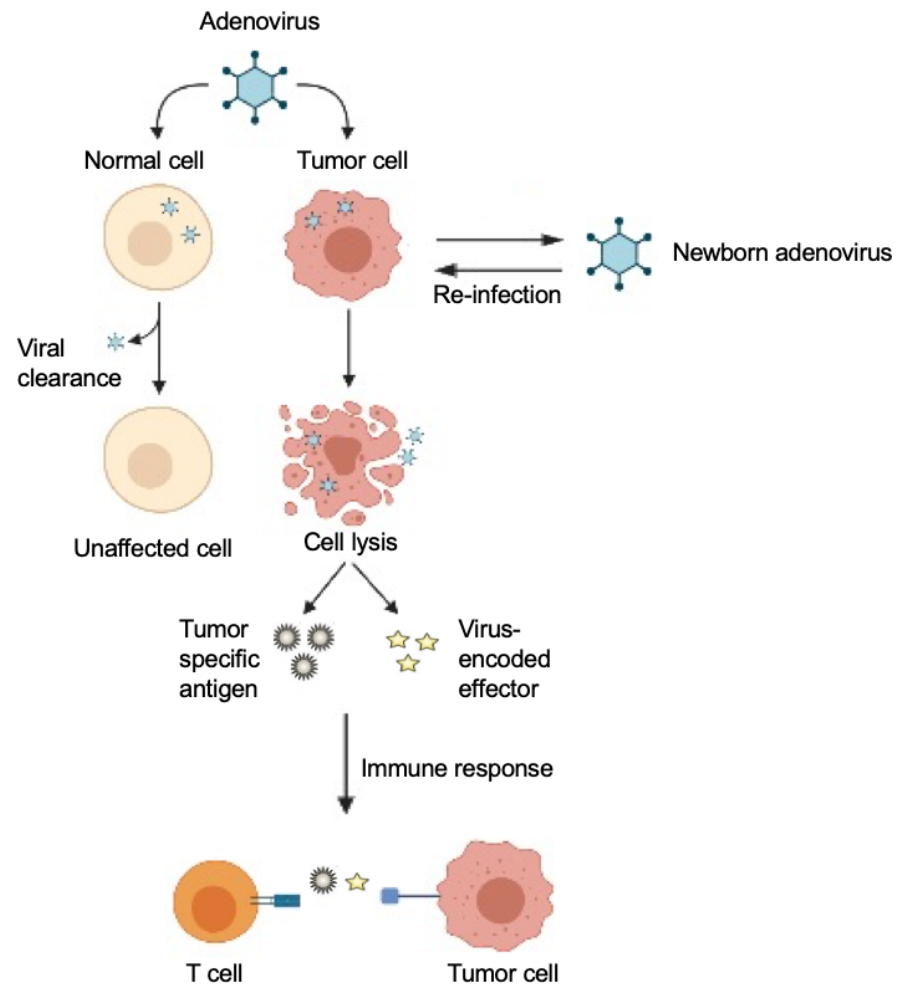

Fig. 1. Adenovirus infection of both tumor and normal cells to induce cell lysis and immune response to the cancer cell. Prior to infection, the adenovirus is loaded and modified with specific genes that allow viral replication only in tumor cells. After cell lysis, the adenovirus stimulates an immune response via tumor specific antigens and virusencoded effectors that have now been released. Figure is adapted from Huang et al. (2019). Created with BioRender.com. subsystem and makes an output decision (Fig. 3). Here, the usage of biological complex logic gates can be employed, which depending on the type of gate, uses a promoter, a repressor, an activator, or combinations of the three (Siuti et al., 2013, Kim et al., 2018, Gao et al., 2019). These gates allow for specificity of the induction or suppression of specific output protein expression that allow for viral replication and immune system responses. Since tumor cells and normal cells display differential expression of different types of mRNA and microRNA (miRNA), many of these biological gates respond to RNA levels or cellular transcription factors (Gao et al., 2019).

The output subsystem is the last subsystem constructed in smart microbial engineering. The decision made by the processing subsystem causes an actuator to trigger a response based on the conditions detected in the cell (Fig. 3). Typically, this involves some form of gene expression regulating event that might be involved in regulating cell growth, controlling viral replication, or in the recognition of the target cell by the immune system (Kim et al., 2018, Gao et al., 2019). In the past, conventional genetic engineering of oncolytic viruses only made use of a biosensor and an actuator. However, with smart engineering, the specificity of recognition of cancer cells can be improved (Gao et al., 2019, Huang et al., 2019).

\section{2 | IMMUNOTHERAPY AND VIROTHERAPY AGAINST CANCER CELLS}

\section{Specific Targeting of Cancerous Cells}

There are many methods through which tumor cells are recognized as being different from normal cells, allowing the induction of viral replication and stimulation of the immune system to be selectively elicited in such affected cells (Li et al., 2021). To allow for the precise control of the identification system, multiple cancer-specific biomarkers can be sensed and then integrated. High specificity can be achieved with an engineered virus that only becomes cytolytic when multiple cancer specific markers are detected (Xie et al., 2011). Many of these tissue-specific signals include promoters that are activated in cancer cells and/or miRNA, proteins, and mRNA that are specific to or highly enriched in cancer cells (Xie et al., 2011).

\section{$R b$ and Cancer Cells}

Adenovirus replication is controlled by the viral E1A protein. E1A binds cellular $\mathrm{Rb}$ protein and in doing so, releases the cellular transcription factor $\mathrm{E} 2 \mathrm{~F}$ from $\mathrm{Rb}$ mediated inhibition (Wold \& Horowitz, 2007). The free E2F is hijacked by the adenovirus to transcribe viral genes. Adenoviruses lacking E1A are thus unable to replicate in normal cells as $\mathrm{Rb}$ 

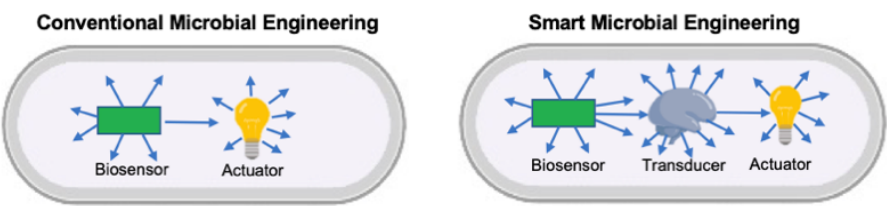

Fig. 2. Conventional microbial engineering in comparison to smart microbial engineering. Conventional engineering relies on the optimization of an output subsystem however, a smart form of engineering allows the virus to respond to an assortment of different signals to increase the specificity of the response. Figure adapted from Gao et al. (2019). Created with BioRender.com.

inhibits E2F, preventing expression of viral genes (Heise et al., 2000). Tumor cells often $h$ ave inactive $R b$ thus, an E1A deletion virus can replicate in and kill the cancer cell (Heise et al., 2000, Martinez-Sanchez et al., 2021). This was the first mechanism used to achieve oncolytic activity but was not very specific. More advanced oncolytic adenoviruses have employed specific mutations in the E1A gene that prevent the $\mathrm{E} 1 \mathrm{~A}$ protein from binding to $\mathrm{Rb}$ while still promoting viral replication (Russell et al., 2012). Another mechanism that controls viral replication in normal cells is a checkpoint regulated by the cellular transcription factor p53 (Moxley \& Reisman, 2021).

\section{p53 and Cancer Cells}

Improved specificity for killing tumor cells has also been achieved by engineering synthetic circuitry to exploit the loss of checkpoint controls in cancer cells. The tumor suppressor p53 is a component of a checkpoint mechanism that regulates diverse cellular processes including, apoptosis, autophagy, and cell-cycle arrest in response to chromosome damage, errors in DNA replication or mitosis (Lees et al., 2021). In many types of human cancers, genetic alterations cause p 53 to be inactivated (Tazawa et al., 2013). This leads to uncontrolled cell growth and tumor formation. Ramachandra et al. (2001) exploited the combination of loss of p53 in tumor cells and the viral requirement to express its E2 genes to replicate. They constructed a fusion of the E2F-DNA binding domain to the $\mathrm{Rb}$ transcriptional repression domain and placed this under the regulation of a p53 regulated promoter (Fig. 4). In normal cells with functional p53, this antagonist will repress the expression of the viral E2 gene, thus inhibiting viral replication (Ramachandra et al., 2001). However, in tumor cells with reduced p53 function, the p53-responsive promoter will be inactive, leading to the reduced expression of the E2F antagonist. This means E2F is free to bind and activate viral E2 genes in the cancerous cells resulting in viral replication and thus increased killing of those tumor cells(Fig. 4). This demonstrates the utility of a relatively simple circuit
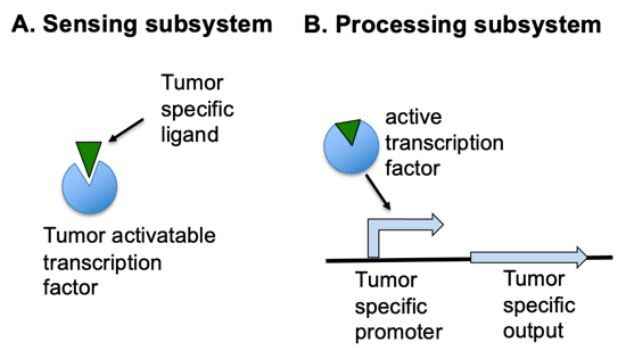

C. Output subsystem

Fig. 3. Subsystems of an engineered virus. (A) Sensing subsystems may consist of a transcription factor that responds to a tumor-specific molecule and becomes active. (B) The activated biosensor then acts on a processing or decision-making subsystem, if activated this subsystem will proceed to drive an output system. (C) Output systems may be composed of any of a variety of proteins that lead to killing of the tumor cell. Some examples shown include pro-drug activating enzymes that convert a harmless compound into a lethal drug that kills the tumor cell, cytotoxic proteins that induce cell death, immune system modulators that induce an immune response against the tumor cells, and viral proteins that stimulate viral replication and induce cell killing. The combination of these systems allows highly selective killing of tumor cells while sparing normal cells. Figure adapted from Kim et al. (2018).

relying on a single input signal, the presence or absence of p53 function (Ramachandra et al., 2001).

\section{Cancer Cell Recognition with Multi-Input miRNA Based Logic Circuit}

miRNAs are small, non-coding RNA molecules that typically function as post-transcriptional regulators of gene expression that modulate a variety of cellular physiological processes (Rovira-Rigau et al., 2019). Some miRNAs function in normal cells as tumor suppressors or oncogenes (Peng \& Croce, 2016). The dysregulation of these miRNAs has been shown to affect cancer hallmarks, including uncontrollable growth, resisting apoptosis, evading the immune system, inducing invasion and metastasis, and angiogenesis (Peng \& Croce, 2016). In many cases, such regulatory miRNAs are found in reduced abundance or overexpressed in cancer cells and thus may act as highly selective biomarkers for particular types of cancer cells (Kabzinski et al., 2021, Zhang et al., 2021).

The specificity of miRNA expression can be used in designing a genetic circuit in an adenovirus that selectively performs its actions in cancer cells by sensing the presence and/or absence of specific miRNAs. A sensor motif can be constructed that allows for output expression of a given protein if only tumor-specific miRNAs are present and normal cell miRNA species are absent (Xie et al., 2011). Fig. 5A depicts an example of a simple circuit regulated by tumour-specific miRNA. In the absence of tumor-specific miRNA, the virus expresses a transcriptional activator $[\mathrm{A}]$ that induces the expression of a repressor protein $[R]$ that then represses 


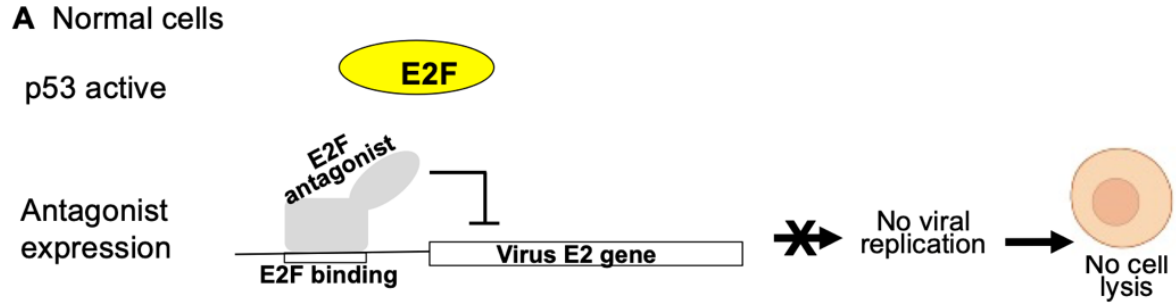

B Tumor cells

$\Delta \mathrm{p} 53$

No antagonist expression


Fig. 4. A p53 dependent E2F antagonist allows viral replication specifically in checkpoint defective tumor cells. (A) When an adenovirus harboring an E2F antagonist regulated by a p 53 inducible promoter infects a normal cell with functional p53, the E2F antagonist is induced and binds the viral E2 promoter and blocks viral replication. (B) When the virus infects a tumor cell lacking $\mathrm{p} 53$ function, no antagonist is expressed and the viral E2 genes are activated by cellular E2F thus inducing viral replication and tumor cell lysis. Figure adapted from Ramachandra et al. (2001). Created with BioRender.com. expression of viral genes, thus inhibiting viral replication and the normal cell is unharmed. The activator and repressor genes are designed such that they are silenced by tumor-specific miRNA, thus in the presence of tumor miRNA, the viral genes are expressed and the tumor cell is killed (Fig. 5A). A more complex circuit that detects both normal cell-specific miRNA and tumor-specific miRNA is shown in Fig. 5B. This virus expresses a repressor protein $[\mathrm{R}]$ that represses a transcriptional activator protein $[\mathrm{A}]$ which induces expression of the output viral genes [O]. In normal cells lacking tumorspecific miRNA, the normal miRNA silences the activator $[\mathrm{A}]$ and viral gene output $[\mathrm{O}]$, thus inhibiting viral replication and sparing the normal cell. In contrast, the presence of tumor miRNA will silence the repressor [R], allowing expression of the activator $[\mathrm{A}]$ and the output viral gene expression $[\mathrm{O}]$, leading to viral replication and tumor cell death (Fig. 5B). More complex circuit have been constructed allowing for a combination of inputs that achieve a high specificity in distinguishing between normal and tumor cells (Xie et al., 2011).

\section{Arming Oncolytic Adenoviruses for Improved Tumor Killing}

While oncolytic adenoviruses have the potential to kill tumor cells, extensive genetic engineering has been utilized to increase their effectiveness in vivo. These efforts have been focusing on "arming" oncolytic adenoviruses with cytolytic transgenes. The strategies employed have included engineering viruses that express pro-drug converting enzymes that make tumor cells vulnerable to drugs like gangcyclovir and 5-fluorocytosine(Freytag et al., 1998, Wildner et al., 1999). Additionally, adenoviruses have been engineered to overexpress transgenes such as the adenovirus death protein TRAIL (tumor necrosis factor-related apoptosis-inducing ligand) to trigger apoptosis, and RNase fused to a tumor ligand to degrade tumor cell RNA (Doronin et al., 2003, Sova et al., 2004, Fernandez-Ulibarri et al., 2015). All of these engineered viruses display improved tumor cell killing in cell culture and in animal models. Further advances on improving the effectiveness of virotherapy have been directed toward engaging the immune system to assist in tumor cell killing and establish an immune response to the tumor cells.

\section{3 | IMMUNE AND VACCINATION RESPONSES BY THE IMMUNE SYSTEM AGAINST CANCER CELLS}

\section{Introduction to Immune Responses}

The immune system is an interactive network of organs, cells, cytokines, and other small molecules involved in host defence, most notably in infections and tumors. All immune cells are developed in the bone marrow and either mature there or in the thymus (Chaplin, 2010). The bone marrow contains two main types of progenitor stem cells: the myeloid and the lymphoid cells (Storey \& Jordan, 2008). The myeloid stem cells can mature into innate immune cells such as monocytes, macrophages, mast cells and dendritic cells, which are important in the first line of defence against infection. The lymphoid stem cell can develop into two main types of the adaptive immune cells, the $\mathrm{B}$ cells and the $\mathrm{T}$ cells (Storey \& Jordan, 2008). The B and T cells are responsible for immunity and to mount responses based on previous exposure. Natural killer (NK) cells are also derived from the lymphoid stem cells and have properties of the innate and adaptive immune cells (Vivier et al., 2008). Vaccination is the process through which immune memory is acquired after a foreign entity is encountered. Antitumor immunity can be achieved through exposure of cancer-specific antigens to B cells and helper $\mathrm{T}$ cells, which can help defend against that specific cancer, if encountered again (Chaplin, 2010).

The immune system is a major target in cancer treatment in order to improve the management of tumors (Kiyotani et al., 2021). Oncolytic virotherapy has now evolved 
to include modulation of the immune system with cytokines and their antagonists as well as allow for increased therapeutic vaccination against tumor cells (Huang et al., 2016). Engineered viruses have the potential to disrupt immunosuppression within the tumor environment and reactivate antitumor immunity, but have yet to live up to their therapeutic potential (Zhang \& Liu, 2020). This portion of the review will focus on the actions performed by smart engineered adenoviruses to activate the immune system after tumor cell lysis. This is necessary to allow for the recruited immune cells to recognize and kill the surrounding tumors, as well as to allow for antitumor immunity. Cell mediated immunity involves the activation of antigen specific $\mathrm{T}$ lymphocytes while humoral immunity involves the priming of B cells to produce antibodies, both of which are used to elicit antitumor vaccination processes (Parkin \& Cohen, 2001). Several papers will be dissected to show the methods by which


Fig. 5. Biological circuits responding to single or multiple inputs to provide selective responses. Genes in the adenovirus genome are depicted as tan colored boxes, RNA transcribed from those genes is shown as a black squiggle line, transcriptional repressor, $\mathrm{R}$, and activator, $\mathrm{A}$, while proteins are shown as ovals. Tumor-specific miRNA (green squiggle line), normal cell miRNA (blue squiggle line). (A) Single input circuit that responds the presence of tumor cell-specific miRNA. A constitutively expressed activator protein $[\mathrm{A}]$ is transcribed from gene $\mathrm{A}$. This activates transcription of a gene encoding a repressor protein $[R]$ which inhibits the expression of an output protein $[\mathrm{O}]$ needed for viral replication. The tumor specific miRNA can bind to and silence the mRNA encoding the repressor, thus allowing for the expression of protein [O], viral replication and cell lysis. The miRNA can also inhibit the activator in this system, which decreases the expression of the repressor, thus allowing expression of output viral protein [0] and cell lysis. (B) Circuit responding to multiple inputs. A constitutively expressed repressor $[R]$ inhibits expression of an activator [A] that induces an output protein [O] required for viral replication. The normal cell miRNA inhibits expression of the activator thus preventing viral replication and cell killing. In contrast, a tumor specific miRNA will inhibit production of the repressor, thereby allowing the activator to elicit expression of the viral replication response with subsequent cell killing. Figure adapted from Xie et al. (2011). the smart oncolytic adenovirus allows for vaccination against tumor cells as well as selectively activating immune cells to recognize only affected cancerous cells.

\section{Immune and Vaccination Responses to Cancer Cells}

For an anti-cancer immune response to be activated by an oncolytic virus leading to effective killing of cancer cells and later immunity, a series of events must be initiated by the oncolytic virus and allowed to proceed in a stepwise fashion (Chen \& Mellman, 2013). The cancer-immunity cycle seen in Fig. 6 shows these steps as well as the type of immune cells associated with them. Upon lysis of cancer cells, antigens are released into the tumor microenvironment (step 1). These antigens are presented to $T$ cells via dendritic cells and other antigen presenting cells (APCs) (step 2). The activation of these T cells (step 3) as well as the presence of the released cancer antigens leads to the recruitment and infiltration of other $\mathrm{T}$ cells, most notably cytotoxic T cells (CTLs) to the tumor site (steps 4 and 5). Antitumor immunity is also elicited via antigen presentation by APCs. This leads to future recognition and efficient killing of the cancer cells by T cells (steps 6 and 7).

\section{Activation of Immune and Vaccination Responses by Adenoviruses}

There are numerous methods by which an adenovirus can be modified or made to induce an immune response after lysis of cancerous cells. One method is to embed immunostimulatory factors such as granulocyte-macrophage colony-stimulating factor (GM-CSF), TNF- $\alpha$, or Interleukins (IL)-2, IL-12, IL-15, IL-18, and IL-24 into the genomes of the adenovirus (Goradel et al., 2019). Many of these factors have antitumor properties that could be related to stimulation of dendritic cells, which are APCs involved in antitumor immunity (Fig. 6). They can also be involved with the direct recruitment of NK cells, which kill cancer cells, as described by step 7 of the cancer-immunity cycle (Fig. 7) (Goradel et al., 2019). $T$ cells are particularly important in the immune response as they activate other immune cells, modulate the immune response, and produce cytokines, which are secreted molecules that recruit other immune cells to the site of tumor lysis (Storey \& Jordan, 2008).

A vaccination process can also be used to allow for antitumor immunity by the immune system via antigen presentation (Fig. 7). Here, tumor antigens are presented to a special type of $\mathrm{T}$ lymphocyte using dendritic cells. However, many tumor cells are evolved to produce immune-inhibitory factors such as IL-10, TGF- $\beta$, and vascular endothelial growth factor (VEGF), which minimize the efficacy of the dendritic cells (Elmusrati et al., 2021, Farlow et al., 2021). Modifications 
of the adenovirus including the inclusion of a repressor for VEGF expression in the tumor cell could help promote dendritic cell efficacy and allow for increased immune response (Goradel et al., 2019, Wang, Zhong, et al., 2021).

Modified adenovirus can also help in the priming, activation and proliferation of several immune cells as shown in the cancer-immunity cycle (Farrera-Sal et al., 2021). An increased immune response also occurs when these oncolytic viruses help in trafficking immune cells to the site of tumor cell lysis, in addition to increasing the permeability of the cancer cells to these immune cells (step 4 in Fig. 6). Overall, oncolytic virotherapy aims at increasing the recognition of tumor cells by Tlymphocytes (Heidbuechel \& Engeland, 2021). This helps in killing surrounding cancer cells as well as ensuring antitumor immunity against the specific cancer type.
Oncolytic viruses are usually engineered to only allow for selective replication in cancer cells (Fig. 8). This leads to lysis of the cancer cell with release of infectious virus, allowing for surrounding tumor cells to be infected and ultimately lysed (Fig. 8). Tumor cell lysis also releases tumor antigens and immunostimulatory molecules, which attract many immune cells to the tumor microenvironment (Marelli et al., 2018). This is referred to as making the tumor "warm" (Marelli et al., 2018). In this context, "warm" indicates that the tumor environment is infiltrated by pro-inflammatory cytokines and $\mathrm{T}$ cells involved in inflammation and induction of an immune response (Duan et al., 2020). The activation of the immune system leads to an antiviral response and significant antitumor responses, mainly to kill surrounding tumors and elicit antitumor immunity (Zhao et al., 2021).

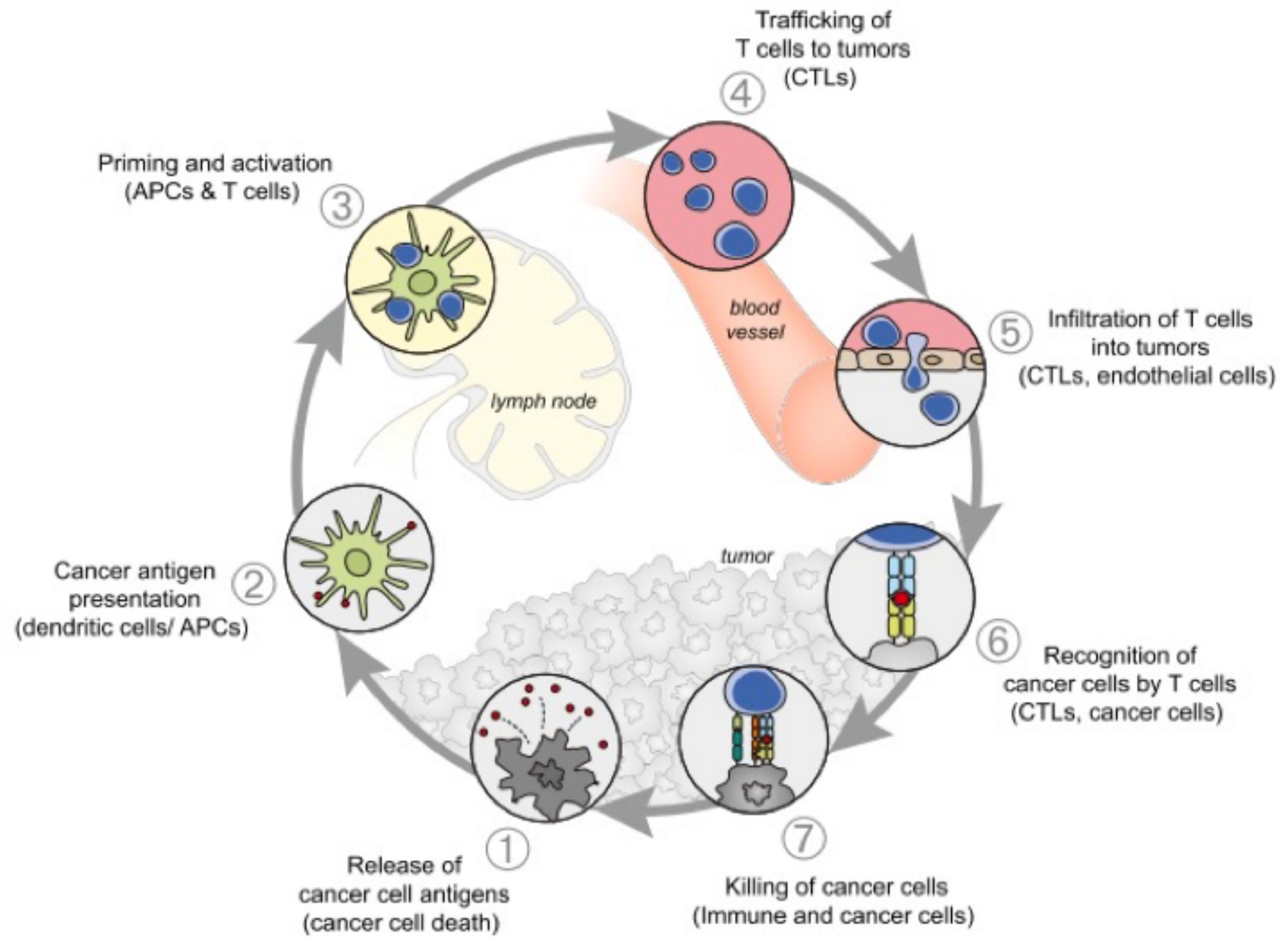

Fig. 6. The Cancer-Immunity Cycle: The process of effective killing and immunity induced by immunotherapy usually follows a cyclic process. The cycle is divided into 7 steps, starting with the release of cancer cell antigens, following cell lysis, and ending with the killing of surrounding cancer cells by the immune cells. Each step above has a brief description along with the type of immune cell involved. APCs are the Antigen Presenting Cells while CTLs are the cytotoxic T Lymphocytes. Figure reprinted with permission from Chen \& Mellman (2013). 


\section{4 | CURRENT APPLICATIONS AND RESEARCH}

\section{Genetic Engineering of Recombinant Adenoviruses \\ Expressing Immuno-Stimulatory Molecules Can Increase \\ Tumor-Targeted Immune Responses}

Current research with smart oncolytic viruses focuses on two main hallmarks of cancer: the ability of cancer cells to evade the immune system and programmed cell death and their resistance to inhibitory signals preventing their growth (Wang, Zhong, et al., 2021). Multiple interconnected pathways between cancer and cells of the immune system converge in the development of a tumor environment where cancer cells can evade immune detection and programmed cell death (Huang et al., 2016).

The immune system usually works to combat tumor development through the activation and proliferation of dendritic cells, macrophages, and NK cells (Pardoll, 2012). These actions are usually counteracted by the production of immunosuppressive cells and cytokines by the tumor (Pardoll, 2012, Elmusrati et al., 2021). Immunostimulatory gene therapy focuses on tilting the suppressive tumor microenvrionment toward immune cell activation (Wang, Zhong, et al., 2021). Oncolytic viruses, and especially adenoviruses, have been demonstrated to be effective gene therapeutic vehicles for expressing immunostimulatory proteins within the tumor microenvironment to elicit antitumor immunity (Loskog, 2015, Wang, Xue, et al., 2021). This emerging therapeutic strategy has also been hypothesized to be an improved method of inducing apoptosis selectively in cancer cells and of overall antitumor immunity against specific cancer types (Peter \& Kuhnel, 2020). Some of the immunostimulatory molecules employed in cancer therapy include OX40, CD40 and GM-CSF (granulocyte macrophage colony-stimulating factor) (Peter \& Kuhnel, 2020). The interaction between OX40 ligand (OX40L), a member of the tumor necrosis factor family, and its receptor, regulates the production of cytokines and effector $\mathrm{T}$ cells involved in activating immune responses to a tumor site (Croft et al., 2009). CD40 is a cell surface receptor that is present on all APCs and activated B cells (Huang et al., 2016). The interaction between the CD40 ligand (CD40L) and its receptor enhances antigen presentation on dendritic cells and promotes $\mathrm{T}$ cellmediated immunity. GM-CSF is a cytokine involved in the proliferation and maturation of dendritic cells and macrophages, and thereby increases a T-cell mediated antitumor response (Bullock, 2021, Petrina et al., 2021). Engineering immunostimulatory genes into smart oncolytic adenoviruses will allow for them to facilitate antitumor responses via the immune system with the aim to promote



Fig. 7. Activation of inflammatory and immunization responses after infection by an oncolytic adenovirus. After cell lysis, the release of cytokines and damage (or danger) associated molecular pattern (DAMP) molecules induces the trafficking and proliferation of monocytes, macrophages, and NK cells, which further kill surrounding tumor cells in the process of pyroptosis. The damage caused to the cell by the replication of the virus induces necrosis leading to release of antigens and other molecules from the cell. Oncolytic adenoviruses also induce antigen presentation on Dendritic Cells (DC), which helps activate the antigen-specific T cells. This is important for allowing the immune system to develop antitumor immunity to fight re-infection. Figure adapted from Song et al. (2019). Created with BioRender.com.

immunity against subsequent cancer recurrences and metastasis.

\section{Engineering Adenoviruses with Pro-Inflammatory Molecules} Induces Tumor Suppression by the Immune System

In a test of the ability of an engineered virus to induce an immune response against tumors, Andarini et al. (2004) engineered a recombinant adenovirus, AdOX40L, expressing an OX40L gene. This modified adenovirus encoded a simple detection circuit based on a defective E1A gene that rendered the virus incapable of replicating in normal cells and was made to specifically target melanoma tumor cells (Andarini et al., 2004). When a group of mice with established melanoma tumors were transduced with the engineered virus, the authors observed a substantial reduction in tumor growth and volume relative to control mice or mice infected with a non-OX40L expressing adenovirus (Andarini et al., 2004). Similar reductions in tumor growth were observed in mice that had been implanted with Lewis lung carcinomas and colon tumors (Andarini et al., 2004). Further analysis of the immune response triggered by the engineered virus demonstrated an increase in tumor cell specific $\mathrm{CD} 4+/+$ and $\mathrm{CD} 8+/+\mathrm{T}$ lymphocytes infiltrating the tumors. These were shown to 
display tumor-specific cytotoxicity (Andarini et al., 2004). Interestingly, the authors reported that CD4-/- and CD8-/mice displayed reduced tumor killing by the engineered virus, consistent with a model whereby the engineered virus induced tumor-specific killing by the host immune response (Andarini et al., 2004). The administration of the OX40L expressing virus overall showed a significant suppression of tumor growth and prolonged survival in the treated mice.

Koski et al. (2010) employed a similar strategy to construct recombinant adenovirus, Ad5/3-D24-GMCSF, with an E1 region deletion and expressing GM-CSF. Systemic infusion of recombinant GM-CSF in cancer therapies is compromised by the induction of immunosuppressor effects by the tumor (Petrina et al., 2021). However, local production of GM-CSF only in infected tumor cells may ensure high local concentration within the tumor microenvironment while minimizing systemic exposure to normal cells (Koski et al., 2010). In immune-competent Syrian hamsters, administration of Ad5/3-D24-GMCSF in combination with injection of low doses of the chemotherapeutic drug cyclophosphamide resulted in a significant reduction in the growth of aggressive pancreatic tumors when compared to hamsters injected with just cyclophosphamide (Koski et al., 2010). The investigators also administered the recombinant Ad5/3-D24-GMCSF adenoviruses to 21 human patients with advanced cancers unresponsive to available treatments. The treatment yielded reductions in common tumor marker values, however tumor suppression in human patients could not be concluded because of a lack of other assessment tools (Koski et al., 2010).

Preclinical and clinical trials with recombinant CD40L genes have proven to be very successful in promoting antitumor effects and immunity in murine models and human cancers (Tong \& Stone, 2003). This makes combining CD40L with the use of oncolytic adenovirotherapy very attractive. Gomes et al. (2009) constructed adenovirus AdEHCD40L with an elaborate biosensor designed to selectively allow replication in breast cancer cells. The E1A gene was placed under the regulation of a hybrid promoter with an estrogen response element (ERE) and hypoxia response element (HRE). Thus, E1A was expressed only in tumor cells and viral replication was limited to those cells. This virus also expressed CD40L (Gomes et al., 2009). To test for the efficacy of the recombinant virus, in vivoanalysis was carried out with human breast cancer cells transplanted into mice. It was observed that administration of the oncolytic AdEHCD40L adenovirus led to a significant reduction in tumor growth, about $\mathbf{9 9 . 9 \%}$, compared to less pronounced reductions with either administration of an adenovirus not expressing CD40L or by injection of CD40L protein alone (Gomes et al., 2009). Yang et al. (2014) constructed a similar smart adenovirus, AdPL-PPT-E1A, with the viral EIA gene under the regulation of a prostate cancer specific promoter armed with fusion gene of prostate-specific antigen and CD40L. Treatment with the recombinant virus supressed the tumor growth significantly in a mouse model of prostate cancer (Yang et al., 2014). Targeted delivery of GM-CSF and/or CD40L by adenoviruses appear to be a promising tool for the treatment of metastatic solid tumors (Huang et al., 2016). However, research is still being performed to fully utilize and fine tune recombinant adenoviruses in order to effectively reduce the growth and metastasis of tumor cells.

Engineering Adenoviruses with Pro-Inflammatory Molecules Induces Increased T Cell Proliferation and Cytokine Secretion

An important component of oncolytic virus strategies is activation of the immune system (Peter \& Kuhnel, 2020). In a further investigation of the potential for the $O X 40 \mathrm{~L}$ expressing adenovirus to induce an immune response to tumor cells, Andarini et al. (2004) injected mice with lymphoma cells expressing chicken ovalbumin (OVA) as a marker for the tumor cells. Treatment of the animals with a recombinant adenovirus, AdOX40L, led to reduction in tumor growth but most importantly, the treatment induced the appearance of CD4+/+ T cells that rapidly proliferated when presented with the OVA antigen in vitro(Andarini et al., 2004). These CD4+/+ $\mathrm{T}$ cells also displayed significantly greater secretion of INF- $\gamma$ than did $\mathrm{CD} 4+/+\mathrm{T}$ cells induced by a control adenovirus infection (Andarini et al., 2004).

Administration of the recombinant GM-CSF producing oncolytic adenovirus to human patients with advanced cancers also yielded promising results in regard to cellular T cell production and cytokine secretion (Koski et al., 2010). It was observed that there was a general increase in CD8+ lymphocytes against the adenovirus as well the tumor marker survivin (Koski et al., 2010). However, there was also a decrease of anti-survivin specific $\mathrm{T}$ lymphocytes in some patients, leading to inconclusive results (Koski et al., 2010). A more recent study using the recombinant GM-CSF producing adenovirus in a Phase I clinical study yielded improved antitumor responses, especially adaptive cellular responses in 12 patients presenting late-stage solid-state cancers of different types including ovarian cancer, soft tissue sarcoma, colorectal cancer, liver, and lung cancer (Ranki et al., 2016). A short-term increase of pro-inflammatory cytokines including interleukins 6 and 8 was observed, indicating a rapid innate immune response activated after administration with the recombinant virus (Ranki et al., 2016). However, 


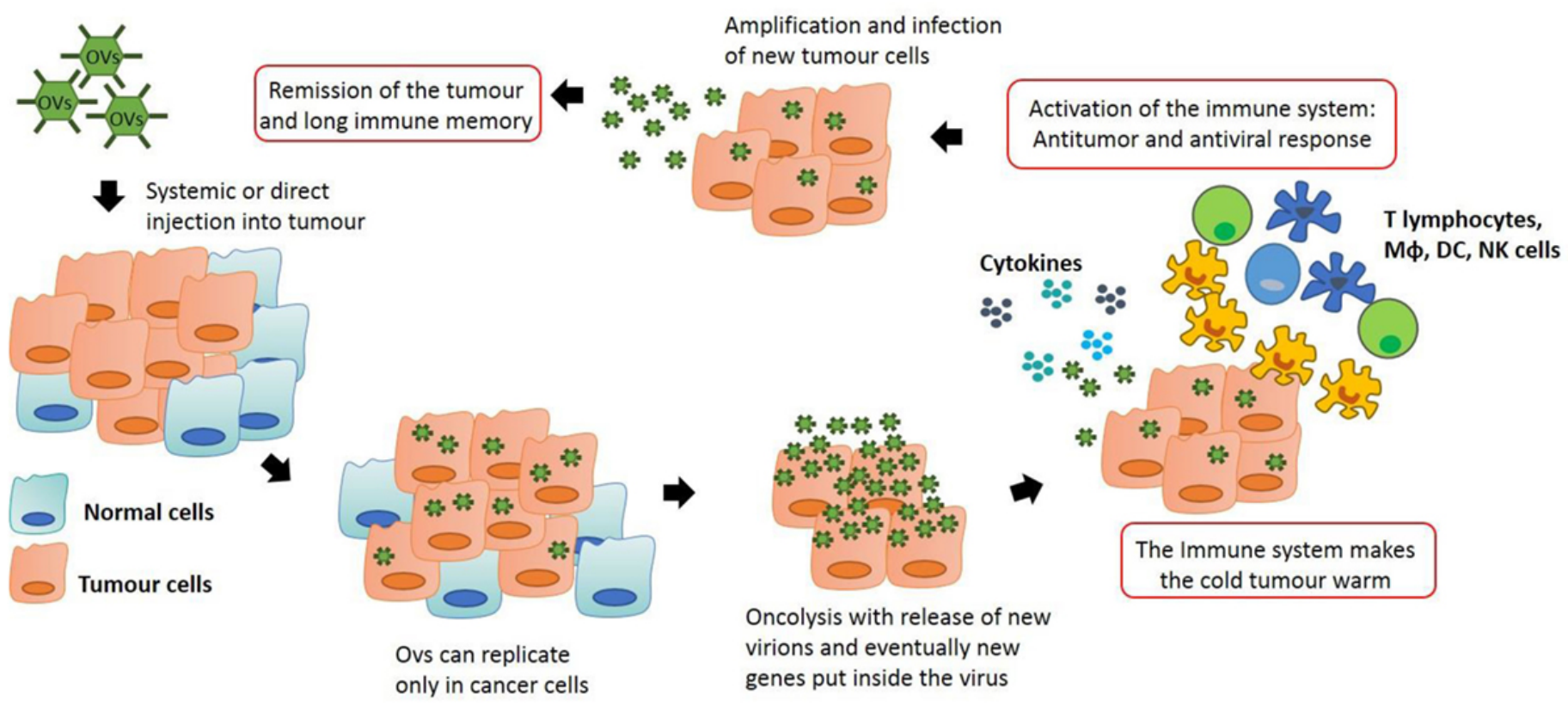

Fig. 8. Immune and vaccination responses elicited by infection with an oncolytic virus. The oncolytic virus is engineered to replicate specifically in the tumor cells. Lysis of the tumor cells leads to release of cytokines and other immunostimulatory molecules. Several immune cells including T lymphocytes, macrophages, monocytes, dendritic cells, NK cells are trafficked to the proximity of tumor cell lysis and there is increased proliferation of these cells. This leads to further killing of surrounding tumor cells with reduction and potentially remission of the tumour achieved. The recruitment of APCs and Tlymphocytes by the oncolytic virus aids in developing long immune memory to recognize that tumor type. Figure reprinted with permission from Marelli et al. (2018).

concentrations of these cytokines did decrease overtime which was interpreted as adaptive immune responses being elicited rather than the earlier innate immune effects. A majority of the patients had increased CD8+ T lymphocyte infiltration to the tumor sites, as well as increased concentrations of macrophages and other $\mathrm{T}$ cells within the tumor microenvironment (Ranki et al., 2016). Overall, administration of this recombinant adenovirus was able to modulate the suppressed immunological environment at tumors and recruit immune cells with cytotoxic properties that could slow down the disease progression and increase survival (Ranki et al., 2016).

Tumor cell lysis releases immunostimulatory signals that help activate the immune system to a tumor microenvironment, but arming the virus further with costimulatory molecules can help improve overall immune efficacy (Diaconu et al., 2012). Taking advantage of the ability of CD40L to promote local cytokine production, Pesonen et al. (2012) administered a recombinant CD40L producing adenovirus to nine cancer patients with advanced solid tumors and found that serum levels of CD40L and RANTES, a cytokine that attracts $\mathrm{T}$ cells and other leukocytes into inflammatory sites, was increased significantly (Pesonen et al., 2012). Diaconu et al. (2012) also observed a similar effect in a murine bladder carcinoma infected with their oncolytic CD40L expressing virus. Overall, the murine CD40L produced by the virus induced secretion of cytokines in the tumor microenvironment, most notably IL-12, IFN- $\gamma$, TNF- $\alpha$, and RANTES (Diaconu et al., 2012). The increased presence of IL12 suggests activation of APCs including dendritic cells and macrophages, while IFN- $\gamma$, TNF- $\alpha$, and RANTES indicate the activation of cytotoxic $\mathrm{T}$ cell infiltration and response to the tumor site (Diaconu et al., 2012). Overall, treatment with CD40L recombinant adenoviruses proved to be important tools in the specific targeting of immune responses to tumor sites in order to enhance cancer cell killing and induce immunity.

\section{Engineering Adenoviruses with Pro-Inflammatory Molecules Activates Antitumor Immunity}

A primary goal of immunomodulation therapy is to activate the immune response against tumors (Huang et al., 2016). Andarini et al. (2004) transduced melanoma tumor cells with the OX40L expressing adenovirus, AdOX40L, before killing the tumor cells and injecting them into mice. The animals were subsequently challenged with live melanoma cells, and while tumors rapidly formed in the mice that had been immunized with mock infected cells, there was a profound reduction in tumor growth in mice that had been immunized with AdOX40L infected tumor cells (Andarini et al., 2004). Vaccination with OX40L-transduced tumor cells increased the number of tumor specific $\mathrm{T}$ helper immune responses and subsequently generated antitumor immunity. Despite the reduction in tumor growth, $80 \%$ of the animals still 
died within 8 weeks of initiating the treatment, indicating that the immunization procedure alone, while effective at slowing tumor growth, was not completely inhibitory. Antitumor immunity has also demonstrated by infecting mice with oncolytic adenovirus encoding tumor-specific antigens (Toes et al., 1997). This strategy was highly tumor specific and yielded a strong cellular immune response with significantly improved survival of animals that were re-challenged by injection with the original tumor cells (Toes et al., 1997).

Oncolytic adenovirotherapy, especially in combination with immunostimulatory molecules, may be an efficient way of augmenting antitumor immunity and vaccinating against metastasized cancers or recurrent tumors (Koski et al., 2010). A recombinant adenovirus expressing GMCSF could attract cytotoxic and helper $T$ cells to the tumor sites in patients with aggressive cancer and thus elicit antitumor immunity (Koski et al., 2010). Ranki et al. (2016) demonstrated increased immunological tumor cell death in patients who were administered an oncolytic GM-CSF producing virus. The adenovirus therapy led to localized release of death associated molecular pattern molecules (DAMPs) like ATP with subsequent dendritic cell stimulation and activation of the cell mediated immune responses (Ranki et al., 2016). T cell infiltration to the tumor site diminished over time, especially in established and progressing tumors, implying an adaptive response in cancer cells and the immunosuppressive tumor environment, as well as the limited abilities of the armed virus (Ranki et al. 2016). Overall, new strategies to better arm oncolytic viruses can help activate cellular immunity to target the tumor microenvironment.

Metastatic tumors are very difficult to treat with current conventional therapies (Menyailo et al., 2021). Smart oncolytic adenovirotherapy can allow for targeted delivery of immunostimulatory molecules to the tumor microenvironment (Wang, Zhong, et al., 2021). This is also augmented by the potential of the virus to elicit immunity that can allow the immune system to respond efficiently to the appearance of tumor growth in another location in the body or in recurrent cancer growth (Zhao et al., 2021). CD40L serves as a very efficient immunostimulatory molecule as it is able to elicit proliferation and infiltration of helper and cytotoxic $\mathrm{T}$ cells and $\mathrm{B}$ cells while also reducing the immunosuppressive activity of the tumor by downregulating regulatory $\mathrm{T}$ cells (Pesonen et al., 2012). Yang et al. (2014) were able to demonstrate that their recombinant virus expressing CD40L helps in promoting the expression of several cytokines necessary for the proliferation and activation of several types of T cells and B cells, most notably CD80, CD83, CD86. This promotes efficient immunity to be built against the tumor.
The interaction between $\mathrm{CD} 40 \mathrm{~L}$ and its receptor also promotes the expression of several immunostimulatory molecules on dendritic cells, thereby stimulating humoral and cell-mediated immunity (Yang et al., 2014). Although recombinant adenoviruses induce tumor-specific immune responses, these responses alone are not sufficient to completely inhibit tumor growth. This approach is rich with potential to be combined with chemotherapeutic approaches which may provide synergistic effects for tumor cell killing and activating the immune system to assist with tumor killing.

Combining Immune Checkpoint Modulation with Production of Immunostimulatory Molecules Can Further Improve the Efficacy of Smart Oncolytic Adenoviruses

Many of the immune system actions activated by virotherapy to kill cancer cells are limited by the immunosuppressive tumor microenvironment, off-target killing of normal cells, and adaptive responses by the cancer cells (Ranki et al., 2016). This can cause reduced survival in a cancer patient and a reduced ability of the oncolytic virus to eliminate tumor growth (Wang, Zhong, et al., 2021). Further engineering oncolytic viruses to increase the specificity of immune responses and combat the adaptive responses of tumors have been hypothesized to help increase survival profiles and the overall efficacy of oncolytic adenoviruses (Wang, Zhong, et al., 2021).

Overexpression of immune inhibitory checkpoint molecules is one of the adaptive responses that allow tumor cells to evade immune system mediated cell death (Dias et al., 2012). Modulating the presence of these inhibitor molecules has been proposed as a method of increasing the efficiency of tumor cell recognition and killing. Some examples of immune inhibitory molecules that dampen the effects of conventional cancer therapy are the programmed death-ligand 1 (PD-L1) and cytotoxic T lymphocyte-associated antigen-4 (CTLA-4) (Pardoll, 2012, Dias et al., 2012). These molecules are commonly overexpressed by tumor cells and limit $\mathrm{T}$ and $\mathrm{B}$ cell priming and activation (Hays \& Bonavida, 2019).

\section{Combining Recombinant Adenoviruses with Immune Checkpoint Modulation Improves Efficacy of Oncolytic Adenoviruses and Increases Survival \\ Oncolytic adenoviruses have the ability to replicate in} and kill tumor cells, but without significant engineering, they fail to induce an effective cell mediated immune response to those tumor cells (Toes et al., 1997). Jiang et al. (2017) combined an OX40L expressing oncolytic adenovirus with injection of an anti-PD-L1 antibody into tumors. PD-L1 is often expressed on the tumor cell surface and acts to dampen the immune 
response against tumor cells (Zou et al., 2016). The PD-L1 antibody blocks any PD-L1 displayed on the tumor cells, thus allowing a more potent immune response to be directed against them (Zou et al., 2016). Jiang et al. (2017) tested the potential of combining an immune checkpoint modulator with an oncolytic virus to elicit tumor-specific immunity in an animal model. The OX40L expressing virus was more effective in killing tumor cells than the adenovirus not expressing OX40L, however, the treatment yielded only $20 \%$ long-term survival (Jiang et al. 2017). Tumor cells in the mouse glioblastoma model displayed an elevated expression of PD-L1 consistent with a low immune response. Indeed, it was observed that the infection of tumor cells with the OX40L expressing virus increased PD-L1 expression (Jiang et al. 2017). It was hypothesized that the elevation of PD-L1 expression in tumor cells might explain their ability to limit the immune response against them. The investigators demonstrated that the combined infection of tumors with the OX40L expressing virus and the injection of a PD-L1 blocking antibody improved the long-term survival of experimental mice to $85 \%$ and resulted in complete tumor regression in survivors (Jiang et al., 2017). Additionally, surviving mice also survived rechallenge with the same tumor cells, indicating that they had developed immunity against the tumor (Jiang et al., 2017).

The combination of oncolytic virus and anti-PD-L1 antibody injection proved effective in cell culture and animal models but has seen limited use in clinical studies (Zhang \& Liu, 2020). In an effort to improve and simplify the therapeutic application, Bunuales et al. (2021) designed an adenovirus and helper virus capable of expressing an anti-PD-L1 antibody. Application of this vector to subcutaneous tumors in a mouse model yielded a reduction in tumor growth and extended survival. While $100 \%$ of the control animals died within 25 days, $40 \%$ of those transduced with the PD-L1 expressing virus were alive after 175 days (Bunuales et al., 2021). The investigators were able to show effective cell killing in the subcutaneous tumor model, however, the approach was much less effective in an animal model of colon carcinoma (Hays \& Bonavida, 2019). These findings highlight the critical role that tumor type and the tumor microenvironment may play in determining treatment effectiveness.

Therapeutic treatment that specifically blocked the PD pathway elicited durable clinical responses in patients with a broad spectrum of cancers. This is because of increased efficiency of $\mathrm{T}$ cell infiltration and effector $\mathrm{T}$ cell function within the tumor microenvironment (Zou et al., 2016). An engineered adenovirus with immune checkpoint modulators may allow for the specific delivery of these molecules to the tumor site and efficient oncolysis and antitumor responses.
CTLA-4 is another immunosuppressor molecule overexpressed by cancer cells that acts as a negative regulator of the proliferation and effector functions of $\mathrm{T}$ cells (Contardi et al., 2005). CTLA-4 acts by interacting with its ligands, CD80 and CD86, which are found on APCs (Sobhani et al., 2021). These interactions inhibit the production of key immunostimulatory cytokines such as IL-2, IL-4 and IFN- $\gamma$. This interaction also upregulates the expression of suppressor T cells and downregulates production of cytotoxic and helper $\mathrm{T}$ cells, which are important for eliciting cancer cell lysis and antitumor immunity (Sobhani et al., 2021). Two monoclonal antibodies against CTLA-4, ipilimumab (MDX-010) and tremelimumab (CP-675206), significantly improved the efficiency of therapeutic treatments in patients with melanoma and other cancers (Kirkwood et al., 2010). The side effects were severe because of the exposure of normal tissue to the treatment (Kirkwood et al., 2010), therefore, the use of recombinant viruses that can specifically target tumor cells in combination with CTLA-4 antibodies has been proposed as a way of increasing safety and efficacy of the treatment. Dias et al. (2012) constructed an oncolytic adenovirus expressing an antibody specific for CTLA-4 to examine the elicited antitumor efficacy and immunity. Administration of the engineered virus elicited a significant increase of IL-2 in ovarian, prostate, and lung cancer, as well as human cancer cell xenografts, in murine samples, which was taken as evidence that $\mathrm{T}$ cell activation was increased (Dias et al., 2012). Four human patients were also treated with the oncolytic virus and increases in the expression of IL- 2 and IFN- $\gamma$ were observed, suggesting increased $\mathrm{T}$ cell production and activity at the tumor sites (Dias et al., 2012). Stimulation of T cells was also found in patients with advanced cancer, which demonstrates that constructing recombinant oncolytic viruses in this way is key to increasing overall antitumor responses to cancer cells (Dias et al., 2012). The increase of helper T cells necessary for antigen presentation also supports this method as a way of eliciting immunity to fight and protect against tumor growth.

Engeland et al. (2014) constructed a measles virus vector encoding antibodies against both CTLA-4 and PD-L1. This treatment combination was hypothesized to be a method of overcoming the increase of immune checkpoint modulators produced by cancer cells, further decreasing the immunosuppressive nature of the tumor microenvironment, increasing cell lysis, and stimulating antitumor immunity (Engeland et al., 2014). The virus was administered in a murine model of malignant melanoma and analyses showed delayed tumor progression and improved overall survival in comparison to animals infected with a control virus (Engeland et al., 2014). This concept could be applied to a range of other 
oncolytic viruses, like adenoviruses, which have been proven to be even more oncolytic. This also leads the way for future clinical trials that combine oncolytic viruses, immunostimulatory molecules, and checkpoint modulation for cancer treatment.

We can conclude that understanding the immunemediated mechanism of action elicited by oncolytic viruses is important in engineering smart oncolytic viruses to increase the efficacy and specificity of the inflammatory and immunity responses. Adenovirotherapy focused on modulating inhibitory responses of the immune system in order to increase targeting towards cancer cells has yielded improved results compared to previous efforts. This research has demonstrated that using smart engineered adenoviruses with modulatory molecules can significantly improve the survival of a cancer patient and aid in increasing antitumor immunity.

\section{5 | DISCUSSION}

The use of relatively simple biosensor modules has allowed for the construction of viruses that can selectively replicate in and lyse tumor cells. This simple but effective circuitry provides the specificity required for effective therapeutic approaches with little chance of killing normal cells. Despite the specificity provided by these tools, there are several issues that arise from the use of oncolytic adenovirotherapy. A comparative study on the immunotherapeutic efficacy of recombinant Semliki Forest virus and adenoviruses in a murine model for cervical cancer found that the adenovirus was not as effective at eliminating tumor cells and reducing tumor growth (RiezebosBrilman et al., 2007). Few other direct comparisons of adenovirus to other oncolytic viruses have been performed. However, there is evidence from animal models that for some tumor types, oncolytic viruses such as the Myxoma virus may be more effective at inducing tumor killing and enhancing long-term survival (Kellish et al., 2019). This raises the issue as to what the overall efficiency would be if the adenovirus is administered in vivo.

Effective cell killing by adenovirus vectors does appear to require large doses of virus. While adenoviruses are generally safe, some modified adenoviruses have been found to require a high dose of viral particles to elicit satisfactory immune cell inflammatory responses and induce antitumor immunity in a murine cervical cancer model (RiezebosBrilman et al., 2007). Such large doses of viruses might favour antiviral responses in addition to the desired antitumor responses. The comparative study on the immunotherapeutic efficacy of recombinant Semliki Forest virus and adenovirus vector systems in a murine model found that increased quantities were needed in order for the adenovirus to induce the same immune responses as the Semliki Forest virus (Riezebos-Brilman et al., 2007). Both the incomplete killing of tumor cells and the need for high doses of virus in adenoviral therapy may reflect the limited ability of the oncolytic adenovirus to spread among the tumor cells, additionally, the induced antiviral immune response that may limit the duration of the viral spread (Goradel et al., 2020). An additional factor that may contribute to limitations in the effectiveness of adenoviral therapy is that tumor cells are genetically unstable, leading to heterogeneity among the cancer cells within a tumor (Killcoyne et al., 2021). Thus, some cells within a tumor may become resistant to viral killing or in the case of viruses engineered to express immune system modulators, may develop means to avoid the virus-induced immune response.

There are other controversies that arise from using oncolytic viruses, particularly adenoviruses, for cancer therapy that are not addressed in this review. Others include the antiviral response mentioned, the relative level of pathogenicity of the virus, and the specific targeting and delivery of these viruses to the exact site of tumor growth. Some of these points could potentially be improved by engineered circuits that could, for example, enable an oncolytic virus to activate expression of a new capsid protein following replication, allowing it to escape from immune recognition and continue to infect nearby tumor cells. Swanner et al. (2019) also suggest that stem cells could be used as "trojan horses", to traffick the oncolytic virus to the site of tumor growth. This is because many unmodified stem cells have the ability to migrate to sites of injury or inflammation and have been shown to selectively move to tumors. Adenoviruses could also be modified to encode immune-stimulating molecules which increase the overall efficacy of the inflammatory responses by the immune system. A simple genetic switch could be engineered into viruses to allow them to detect specific cytokines and induce or repress expression of an appropriate immune modulatory protein or peptide. Local expression of cytokines by these viruses can help increase the functionality of the immune system, while reducing the risk of systemic toxicity and increasing overall normal cell survival rates (Swanner et al., 2019). This process also comes with the risk of an aggravated immune reaction, a cytokine storm, occurring because of the mass influx of cytokines being released by both the adenovirus and immune cells (Chhabra \& Kennedy, 2021). This can result in adverse symptoms being experienced by the patient including a high fever and sometimes nausea, low blood pressure, and seizures. 
Research is being undertaken to understand and finetune this process of modulating the immune system to elicit an appropriate response. Making this treatment sufficient to kill tumor cells without affecting normal cells and disrupting body homeostasis is now a major area of focus. The blockade of inhibitory signals present on tumor cells or T cells can enhance antitumor immune responses, and genes for this can be encoded into the viruses (Swanner et al., 2019). Oncolytic viruses can also disrupt components of the DNA damage response system to help increase the rates of viral replication, cell killing, and recruitment of the immune system (Swanner et al., 2019). The idea of using other effective viruses that induce stronger killing and immunity response against cancer cells, such as with the Herpes Simplex virus (HSV), has also been suggested in the use of oncolytic virotherapy. However, many of these viruses face controversy with their high pathogenicity and the possibility of adverse side effects that might be elicited with their administration (Kangas et al., 2021).

\section{6 | CONCLUSION}

This review shows the promising nature of using smart oncolytic adenoviruses to induce specific immune responses in order to kill cancer cells as well as elicit antitumor immunity that can prevent later re-infection by a specific cancer type. The adenovirus has a large genomic capacity that allows for several genes to be encoded in it, as well as a wide range of tissue tropisms that can be applied to treatments using this virus. The papers examined in this review show the effective oncolytic nature of this virus as well as its ability to induce inflammatory and vaccination responses from the immune system. There are, however, still a variety of issues posed with using this form of cancer therapeutic treatment, mostly concerning the employment of adenoviruses as the oncolytic virus of choice. There are the problems of a low survival rate of normal cells after a vaccination response, antiviral responses by the immune system, and the large dosages of adenovirus needed to elicit an appropriate response, which are often encountered in addition to many other factors. There is some present and future research aimed at understanding the immune mechanism of these oncolytic viruses that focus on improving the efficacy of this oncolytic treatment. Overall, this review serves as a basis for discussing the design of specific adenoviruses that elicit inflammatory responses from the immune system to kill cancer cells as well as induce efficient and specific antitumor immunity against these tumors.

\section{REFERENCES}

Andarini, S., Kikuchi, T., Nukiwa, M., Pradono, P., Suzuki, T., Ohkouchi, S., Inoue, A., Maemondo, M., Ishii, N., Saijo, Y., Sugamura, K., \& Nukiwa, T. (2004). Adenovirus vector-mediated in vivo gene transfer of OX40 ligand to tumor cells enhances antitumor immunity of tumor-bearing hosts. Cancer research, 64(9), 32813287. https://doi.org/10.1158/0008-5472.can-03-3911

Bergelson, J. M., Cunningham, J. A., Droguett, G., Kurt-Jones, E. A., Krithivas, A., Hong, J. S., Horwitz, M. S., Crowell, R. L., \& Finberg, R. W. (1997). Isolation of a common receptor for Coxsackie B viruses and adenoviruses 2 and 5. Science (New York, N.Y.), 275(5304), 1320-1323. https://doi.org/10.1126/science.275.5304.1320

Berk A. J. (2005). Recent lessons in gene expression, cell cycle control, and cell biology from adenovirus. Oncogene, 24(52), 7673-7685. https://doi.org/10.1038/sj.onc.120904

Bullock T. (2021). CD40 stimulation as a molecular adjuvant for cancer vaccines and other immunotherapies. Cellular \& molecular immunology, 10.1038/s41423-021-00734-4. Advance online publication. https://doi.org/10.1038/s41423-021-00734-4

Bunuales, M., Ballesteros-Briones, M. C., Gonzalez-Aparicio, M., HervasStubbs, S., Martisova, E., Mancheno, U., Ricobaraza, A., Lumbreras, S., Smerdou, C., \& Hernandez-Alcoceba, R. (2021). Adenovirus-Mediated Inducible Expression of a PD-L1 Blocking Antibody in Combination with Macrophage Depletion Improves Survival in a Mouse Model of Peritoneal Carcinomatosis. International journal of molecular sciences, 22(8), 4176. https://doi.org/10.3390/ijms22084176

Chaplin D. D. (2010). Overview of the immune response. The Journal of allergy and clinical immunology, $125(2 \mathrm{Suppl}$ 2), S3-S23. https://doi.org/10.1016/j.jaci.2009.12.980

Chen, Y., Hu, S., Shu, Y., Qi, Z., Zhang, B., Kuang, Y., Ma, J., \& Cheng, P. (2021). Antifibrotic Therapy Augments the Antitumor Effects of Vesicular Stomatitis Virus Via Reprogramming Tumor Microenvironment. Human gene therapy, 10.1089/hum.2021.048. Advance online publication. https://doi.org/10.1089/hum.2021.048

Chen, D. S., \& Mellman, I. (2013). Oncology meets immunology: the cancerimmunity cycle. Immunity, 39(1), 1-10. https://doi.org/10.1016/j.immuni.2013.07.012

Chhabra, N., \& Kennedy, J. (2021). A Review of Cancer Immunotherapy Toxicity II: Adoptive Cellular Therapies, Kinase Inhibitors, Monoclonal Antibodies, and Oncolytic Viruses. Journal of medical toxicology: official journal of the American College of Medical Toxicology, 1-13. Advance online publication. https://doi.org/10.1007/s13181-021-00835-6

Contardi, E., Palmisano, G. L., Tazzari, P. L., Martelli, A. M., Falà, F., Fabbi, M., Kato, T., Lucarelli, E., Donati, D., Polito, L., Bolognesi, A., Ricci, F., Salvi, S., Gargaglione, V., Mantero, S., Alberghini, M., Ferrara, G. B., \& Pistillo, M. P. (2005). CTLA-4 is constitutively expressed on tumor cells and can trigger apoptosis upon ligand interaction. International journal of cancer, 1174), 538-550. https://doi.org/10.1002/ijc.21155

Croft, M., So, T., Duan, W., \& Soroosh, P. (2009). The significance of OX40 and OX40L to T-cell biology and immune disease. Immunological reviews, 229(1), 173-191. https://doi.org/10.1111/j.1600-065X.2009.00766.x 
Diaconu, I., Cerullo, V., Hirvinen, M. L., Escutenaire, S., Ugolini, M., Pesonen, S. K., Bramante, S., Parviainen, S., Kanerva, A., Loskog, A. S., Eliopoulos, A. G., Pesonen, S., \& Hemminki, A. (2012). Immune response is an important aspect of the antitumor effect produced by a CD40L-encoding oncolytic adenovirus. Cancer research, 72(9), 2327-2338. https://doi.org/10.1158/0008-5472.CAN-11-2975

Dias, J. D., Hemminki, O., Diaconu, I., Hirvinen, M., Bonetti, A., Guse, K., Escutenaire, S., Kanerva, A., Pesonen, S., Löskog, A., Cerullo, V., \& Hemminki, A. (2012). Targeted cancer immunotherapy with oncolytic adenovirus coding for a fully human monoclonal antibody specific for CTLA-4. Gene therapy, 19(10), 988-998. https://doi.org/10.1038/gt.2011.176

Doronin, K., Toth, K., Kuppuswamy, M., Krajcsi, P., Tollefson, A. E., \& Wold, W. S. (2003). Overexpression of the ADP(E3-11.6K) protein increases cell lysis and spread of adenovirus. Virology, 305(2), 378-387. https://doi.org/10.1006/viro.2002.1772

Duan, Q., Zhang, H., Zheng, J., \& Zhang, L. (2020). Turning Cold into Hot: Firing up the Tumor Microenvironment. Trends in cancer, 6(7), 605-618. https://doi.org/10.1016/j.trecan.2020.02.022

Elmusrati, A., Wang, J., \& Wang, C. Y. (2021). Tumor microenvironment and immune evasion in head and neck squamous cell carcinoma. International journal of oral science, 13(1), 24. https://doi.org/10.1038/s41368-021-00131-7

Engeland, C. E., Grossardt, C., Veinalde, R., Bossow, S., Lutz, D., Kaufmann, J. K., Shevchenko, I., Umansky, V., Nettelbeck, D. M., Weichert, W., Jäger, D., von Kalle, C., \& Ungerechts, G. (2014). CTLA-4 and PD-L1 checkpoint blockade enhances oncolytic measles virus therapy. Molecular therapy: the journal of the American Society of Gene Therapy, 22(11), 1949-1959. https://doi.org/10.1038/mt.2014.160

Farlow, J. L., Brenner, J. C., Lei, Y. L., \& Chinn, S. B. (2021). Immune deserts in head and neck squamous cell carcinoma: A review of challenges and opportunities for modulating the tumor immune microenvironment. Oral oncology, 120, 105420. https://doi.org/10.1016/j.oraloncology.2021.105420

Farrera-Sal, M., Moya-Borrego, L., Bazan-Peregrino, M., \& Alemany, R. (2021). Evolving Status of Clinical Immunotherapy with Oncolytic Adenovirus. Clinical cancer research: an official journal of the American Association for Cancer Research, 2711), 2979-2988. https://doi.org/10.1158/1078-0432.CCR20-1565

Fernández-Ulibarri, I., Hammer, K., Arndt, M. A., Kaufmann, J. K., Dorer, D., Engelhardt, S., Kontermann, R. E., Hess, J., Allgayer, H., Krauss, J., \& Nettelbeck, D. M. (2015). Genetic delivery of an immunoRNase by an oncolytic adenovirus enhances anticancer activity. International journal of cancer, 136(9), 2228-2240. https://doi.org/10.1002/ijc.29258

Freytag, S. O., Rogulski, K. R., Paielli, D. L., Gilbert, J. D., \& Kim, J. H. (1998). A novel three-pronged approach to kill cancer cells selectively: concomitant viral, double suicide gene, and radiotherapy. Human gene therapy, 99), 1323-1333. https://doi.org/10.1089/hum.1998.9.9-1323

Gallardo, J., Pérez-Illana, M., Martín-González, N., \& San Martín, C. (2021). Adenovirus Structure: What Is New?. International journal of molecular sciences, 22(10), 5240. https://doi.org/10.3390/ijms22105240

Gao, C., Xu, P., Ye, C., Chen, X., \& Liu, L. (2019). Genetic Circuit-Assisted Smart Microbial Engineering. Trends in microbiology, 2712), 1011-1024. https://doi.org/10.1016/j.tim.2019.07.005

Gomes, E. M., Rodrigues, M. S., Phadke, A. P., Butcher, L. D., Starling, C., Chen, S., Chang, D., Hernandez-Alcoceba, R., Newman, J. T., Stone, M. J., \& Tong, A. W. (2009). Antitumor activity of an oncolytic adenoviral-CD40 ligand (CD154) transgene construct in human breast cancer cells. Clinical cancer research: an official journal of the American Association for Cancer Research, 15(4), 1317-1325. https://doi.org/10.1158/1078-0432.CCR-08-1360

Goradel, N. H., Mohajel, N., Malekshahi, Z. V., Jahangiri, S., Najafi, M., Farhood, B., Mortezaee, K., Negahdari, B., \& Arashkia, A. (2019). Oncolytic adenovirus: A tool for cancer therapy in combination with other therapeutic approaches. Journal of cellular physiology, 234(6), 8636-8646.

https://doi.org/10.1002/jcp.27850

Goradel, N. H., Negahdari, B., Ghorghanlu, S., Jahangiri, S., \& Arashkia, A. (2020). Strategies for enhancing intratumoral spread of oncolytic adenoviruses. Pharmacology \& therapeutics, 213, 107586. https://doi.org/10.1016/j.pharmthera.2020.107586

Hays, E., \& Bonavida, B. (2019). YY1 regulates cancer cell immune resistance by modulating PD-L1 expression. Drug resistance updates: reviews and commentaries in antimicrobial and anticancer chemotherapy, 43, 10-28. https://doi.org/10.1016/j.drup.2019.04.001

Heidbuechel, J., \& Engeland, C. E. (2021). Oncolytic viruses encoding bispecific T cell engagers: a blueprint for emerging immunovirotherapies. Journal of hematology \& oncology, 14(1), 63. https://doi.org/10.1186/s13045-021-01075-5

Heise, C., Hermiston, T., Johnson, L., Brooks, G., Sampson-Johannes, A., Williams, A., Hawkins, L., \& Kirn, D. (2000). An adenovirus E1A mutant that demonstrates potent and selective systemic anti-tumoral efficacy. Nature medicine, 6(10), 1134-1139. https://doi.org/10.1038/80474

Heise, C., \& Kirn, D. H. (2000). Replication-selective adenoviruses as oncolytic agents. The Journal of clinical investigation, $105(7), 847-851$. https://doi.org/10.1172/JCI9762

Huang, J. L., LaRocca, C. J., \& Yamamoto, M. (2016). Showing the Way: Oncolytic Adenoviruses as Chaperones of Immunostimulatory Adjuncts. Biomedicines, 4(3), 23. https://doi.org/10.3390/biomedicines4030023

Huang, H., Liu, Y., Liao, W., Cao, Y., Liu, Q., Guo, Y., Lu, Y., \& Xie, Z. (2019). Oncolytic adenovirus programmed by synthetic gene circuit for cancer immunotherapy. Nature communications, 1Q1), 4801. https://doi.org/10.1038/s41467-019-12794-2

Jiang, H., Rivera-Molina, Y., Gomez-Manzano, C., Clise-Dwyer, K., Bover, L., Vence, L. M., Yuan, Y., Lang, F. F., Toniatti, C., Hossain, M. B., \& Fueyo, J. (2017). Oncolytic Adenovirus and Tumor-Targeting Immune Modulatory Therapy Improve Autologous Cancer Vaccination. Cancer research, 7714), 3894-3907.https://doi.org/10.1158/0008-5472.CAN-17-0468

Kabzinski, J., Maczynska, M., \& Majsterek, I. (2021). MicroRNA as a Novel Biomarker in the Diagnosis of Head and Neck Cancer. Biomolecules, $11(6), 844$. https://doi.org/10.3390/biom11060844

Kangas, C., Krawczyk, E., \& He, B. (2021). Oncolytic HSV: Underpinnings of Tumor Susceptibility. Viruses, 13(7), 1408. https://doi.org/10.3390/v13071408

Killcoyne, S., Yusuf, A., \& Fitzgerald, R. C. (2021). Genomic instability signals offer diagnostic possibility in early cancer detection. Trends in genetics: TIG, 3711), 966-972. https://doi.org/10.1016/j.tig.2021.06.009

Kellish, P., Shabashvili, D., Rahman, M. M., Nawab, A., Guijarro, M. V., Zhang, M., Cao, C., Moussatche, N., Boyle, T., Antonia, S., Reinhard, M., Hartzell, C., Jantz, M., Mehta, H. J., McFadden, G., Kaye, F. J., \& Zajac-Kaye, M. (2019). Oncolytic virotherapy for small-cell lung cancer induces immune infiltration and prolongs survival. The Journal of clinical investigation, 1296), 2279-2292. https://doi.org/10.1172/JCI121323 
Kim, S. G., Noh, M. H., Lim, H. G., Jang, S., Jang, S., Koffas, M., \& Jung, G. Y. (2018). Molecular parts and genetic circuits for metabolic engineering of microorganisms. FEMS microbiology letters, 365(17), 10.1093/femsle/fny187. https://doi.org/10.1093/femsle/fny187

Kirkwood, J. M., Lorigan, P., Hersey, P., Hauschild, A., Robert, C., McDermott, D., Marshall, M. A., Gomez-Navarro, J., Liang, J. Q., \& Bulanhagui, C. A. (2010). Phase II trial of tremelimumab (CP-675,206) in patients with advanced refractory or relapsed melanoma. Clinical cancer research: an official journal of the American Association for Cancer Research, 16(3), 1042-1048. https://doi.org/10.1158/1078-0432.CCR-09-2033

Kiyotani, K., Toyoshima, Y., \& Nakamura, Y. (2021). Personalized immunotherapy in cancer precision medicine. Cancer biology \& medicine, 18(4), $955-965$. Advance online publication. https://doi.org/10.20892/j.issn.2095-3941.2021.0032

Koski, A., Kangasniemi, L., Escutenaire, S., Pesonen, S., Cerullo, V., Diaconu, I., Nokisalmi, P., Raki, M., Rajecki, M., Guse, K., Ranki, T., Oksanen, M., Holm, S. L., Haavisto, E., Karioja-Kallio, A., Laasonen, L., Partanen, K., Ugolini, M., Helminen, A., Karli, E., ... Hemminki, A. (2010). Treatment of cancer patients with a serotype 5/3 chimeric oncolytic adenovirus expressing GMCSF. Molecular therapy: the journal of the American Society of Gene Therapy, 18(10), 1874-1884. https://doi.org/10.1038/mt.2010.161

Lees, A., Sessler, T., \& McDade, S. (2021). Dying to Survive-The p53 Paradox. Cancers, 13(13), 3257. https://doi.org/10.3390/cancers13133257

Li, Y., Jin, J., \& Bai, F. (2021). Cancer biology deciphered by single-cell transcriptomic sequencing. Protein \& cell, 10.1007/s13238-021-00868-1. Advance online publication. https://doi.org/10.1007/s13238-021-00868-1

Loskog A. (2015). Immunostimulatory Gene Therapy Using Oncolytic Viruses as Vehicles. Viruses, 711), 5780-5791.https://doi.org/10.3390/v7112899

Lou, J., Dong, J., Xu, R., Zeng, H., Fang, L., Wu, Y., Liu, Y., \& Wang, S. (2021). Remodeling of the tumor microenvironment using an engineered oncolytic vaccinia virus improves PD-L1 inhibition outcomes. Bioscience reports, 41(6), BSR20204186. https://doi.org/10.1042/BSR20204186

Malogolovkin, A., Gasanov, N., Egorov, A., Weener, M., Ivanov, R., \& Karabelsky, A. (2021). Combinatorial Approaches for Cancer Treatment Using Oncolytic Viruses: Projecting the Perspectives through Clinical Trials Outcomes. Viruses, 13(7), 1271.https://doi.org/10.3390/v13071271

Marelli, G., Howells, A., Lemoine, N. R., \& Wang, Y. (2018). Oncolytic Viral Therapy and the Immune System: A Double-Edged Sword Against Cancer. Frontiers in immunology, 9, 866. https://doi.org/10.3389/fimmu.2018.00866

Martínez-Sánchez, M., Hernandez-Monge, J., Rangel, M., \& Olivares-Illana, V. (2021). Retinoblastoma: from discovery to clinical management. The FEBS journal, 10.1111/febs.16035. Advance online publication. https://doi.org/10.1111/febs.16035

Menyailo, M. E., Bokova, U. A., Ivanyuk, E. E., Khozyainova, A. A., \& Denisov, E. V. (2021). Metastasis Prevention: Focus on Metastatic Circulating Tumor Cells. Molecular diagnosis \& therapy, 25(5), 549-562. https://doi.org/10.1007/s40291-021-00543-5

Moaven, O., W Mangieri, C., A Stauffer, J., Anastasiadis, P. Z., \& Borad, M. J. (2021). Evolving Role of Oncolytic Virotherapy: Challenges and Prospects in Clinical Practice. JCO precision oncology, 5, PO.20.00395. https://doi.org/10.1200/PO.20.00395

Moxley, A. H., \& Reisman, D. (2021). Context is key: Understanding the regulation, functional control, and activities of the p53 tumour suppressor. Cell biochemistry and function, 39(2), 235-247. https://doi.org/10.1002/cbf.3590

Oosenbrug, T., van den Wollenberg, D., Duits, E. W., Hoeben, R. C., \& Ressing, M. E. (2021). Induction of Robust Type I Interferon Levels by Oncolytic Reovirus Requires Both Viral Replication and Interferon- $\alpha / \beta$ Receptor Signaling. Human gene therapy, 32(19-20), 1171-1185. https://doi.org/10.1089/hum.2021.140

Panagioti, E., Kurokawa, C., Viker, K., Ammayappan, A., Anderson, S. K., Sotiriou, S., Chatzopoulos, K., Ayasoufi, K., Johnson, A. J., Iankov, I. D., \& Galanis, E. (2021). Immunostimulatory bacterial antigen-armed oncolytic measles virotherapy significantly increases the potency of anti-PD1 checkpoint therapy. The Journal of clinical investigation, 131(13), e141614. https://doi.org/10.1172/JCI141614

Pandha, H. S. (2016). Science in Focus - Oncolytic Viruses: New Multifunctional Immunotherapeutics. Clinical oncology (Royal College of Radiologists (Great Britain)), 28(10), 615-618. https://doi.org/10.1016/j.clon.2016.06.014

Pardoll D. M. (2012). The blockade of immune checkpoints in cancer immunotherapy. Nature reviews. Cancer, 12(4), 252-264. https://doi.org/10.1038/nrc3239

Parkin, J., \& Cohen, B. (2001). An overview of the immune system. Lancet (London, England), 3579270), 1777-1789. https://doi.org/10.1016/S01406736(00)04904-7

Peng, Y., \& Croce, C. M. (2016). The role of MicroRNAs in human cancer. Signal transduction and targeted therapy, 1, 15004. https://doi.org/10.1038/sigtrans.2015.4

Pesonen, S., Diaconu, I., Kangasniemi, L., Ranki, T., Kanerva, A., Pesonen, S. K., Gerdemann, U., Leen, A. M., Kairemo, K., Oksanen, M., Haavisto, E., Holm, S. L., Karioja-Kallio, A., Kauppinen, S., Partanen, K. P., Laasonen, L., Joensuu, T., Alanko, T., Cerullo, V., \& Hemminki, A. (2012). Oncolytic immunotherapy of advanced solid tumors with a CD40L-expressing replicating adenovirus: assessment of safety and immunologic responses in patients. Cancer research, 72(7), 1621-1631.https://doi.org/10.1158/0008-5472.CAN-11-3001

Peter, M., \& Kühnel, F. (2020). Oncolytic Adenovirus in Cancer Immunotherapy. Cancers, 12(11), 3354. https://doi.org/10.3390/cancers12113354

Petrina, M., Martin, J., \& Basta, S. (2021). Granulocyte macrophage colony-stimulating factor has come of age: From a vaccine adjuvant to antiviral immunotherapy. Cytokine \& growth factor reviews, 59, 101-110. https://doi.org/10.1016/j.cytogfr.2021.01.001

Ramachandra, M., Rahman, A., Zou, A., Vaillancourt, M., Howe, J. A., Antelman, D., Sugarman, B., Demers, G. W., Engler, H., Johnson, D., \& Shabram, P. (2001). Re-engineering adenovirus regulatory pathways to enhance oncolytic specificity and efficacy. Nature biotechnology, 19(11), 1035-1041. https://doi.org/10.1038/nbt1101-1035

Ramachandran, M., Yu, D., Dyczynski, M., Baskaran, S., Zhang, L., Lulla, A., Lulla, V., Saul, S., Nelander, S., Dimberg, A., Merits, A., Leja-Jarblad, J., \& Essand, M. (2017). Safe and Effective Treatment of Experimental Neuroblastoma and Glioblastoma Using Systemically Delivered Triple MicroRNADetargeted Oncolytic Semliki Forest Virus. Clinical cancer research: an official journal of the American Association for Cancer Research, 23(6), 1519-1530. https://doi.org/10.1158/1078-0432.CCR-16-0925 
Ranki, T., Pesonen, S., Hemminki, A., Partanen, K., Kairemo, K., Alanko, T., Lundin, J., Linder, N., Turkki, R., Ristimäki, A., Jäger, E., Karbach, J., Wahle, C., Kankainen, M., Backman, C., von Euler, M., Haavisto, E., Hakonen, T., Heiskanen, R., Jaderberg, M., ... Joensuu, T. (2016). Phase I study with ONCOS102 for the treatment of solid tumors - an evaluation of clinical response and exploratory analyses of immune markers. Journal for immunotherapy of cancer, 4, 17. https://doi.org/10.1186/s40425-016-0121-5

Riezebos-Brilman, A., Walczak, M., Regts, J., Rots, M. G., Kamps, G., Dontje, B., Haisma, H. Y., Wilschut, J., \& Daemen, T. (2007). A comparative study on the immunotherapeutic efficacy of recombinant Semliki Forest virus and adenovirus vector systems in a murine model for cervical cancer. Gene therapy, 14(24), 1695-1704. https://doi.org/10.1038/sj.gt.3303036

Rovira-Rigau, M., Raimondi, G., Marín, M. Á., Gironella, M., Alemany, R., \& Fillat, C. (2019). Bioselection Reveals miR-99b and miR-485 as Enhancers of Adenoviral Oncolysis in Pancreatic Cancer. Molecular therapy: the journal of the American Society of Gene Therapy, 271), $230-243$. https://doi.org/10.1016/j.ymthe.2018.09.016

Russell W. C. (2009). Adenoviruses: update on structure and function. The Journal of general virology, 90(Pt 1), 1-20. https://doi.org/10.1099/vir.0.003087-0 Russell, S. J., Peng, K. W., \& Bell, J.C. (2012). Oncolytic virotherapy. Nature biotechnology, 30(7), 658-670. https://doi.org/10.1038/nbt.2287

Siegel, R. L., Miller, K. D., \& Jemal, A. (2015). Cancer Statistics, 2015. CA: a cancer journal for clinicians, 65(1), 5-29. https://doi.org/10.3322/caac.21254

Siuti, P., Yazbek, J., \& Lu, T. K. (2013). Synthetic circuits integrating logic and memory in living cells. Nature biotechnology, 31(5), 448-452. https://doi.org/10.1038/nbt.2510

Sobhani, N., Tardiel-Cyril, D. R., Davtyan, A., Generali, D., Roudi, R., \& Li, Y. (2021). CTLA-4 in Regulatory T Cells for Cancer Immunotherapy. Cancers, 13(6), 1440. https://doi.org/10.3390/cancers13061440

Song H, Zhong LP, He J, Huang Y, Zhao YX. Application of Newcastle disease virus in the treatment of colorectal cancer. World J Clin Cases. 2019 Aug 26;7(16):2143-2154. doi: 10.12998/wjcc.v7.i16.2143. PMID: 31531310; PMCID: PMC6718777.

Sova, P., Ren, X. W., Ni, S., Bernt, K. M., Mi, J., Kiviat, N., \& Lieber, A. (2004). A tumor-targeted and conditionally replicating oncolytic adenovirus vector expressing TRAIL for treatment of liver metastases. Molecular therapy: the journal of the American Society of Gene Therapy, 9(4), 496-509. https://doi.org/10.1016/j.ymthe.2003.12.008

Storey, M., \& Jordan, S. (2008). An overview of the immune system. Nursing standard(Royal College of Nursing (Great Britain): 1987), 23(15-17), 47-60. https://doi.org/10.7748/ns2008.12.23.15.47.c6738

Swanner J., Meisen W.H., McCormack R.M., Lewis C.T., Hong B., \& Kaur B. (2019) Current Challenges and Applications of Oncolytic Viruses in Overcoming the Development of Resistance to Therapies in Cancer. In Szewczuk M., Qorri B., \& Sambi M. (Eds.), Current Applications for Overcoming Resistance to Targeted Therapies. Resistance to Targeted Anti-Cancer Therapeutics, vol 20. Springer, Cham. https://doi.org/10.1007/978-3-030-21477-7_3

Tazawa, H., Kagawa, S., \& Fujiwara, T. (2013). Advances in adenovirus-mediated p53 cancer gene therapy. Expert opinion on biological therapy, 13(11), 15691583. https://doi.org/10.1517/14712598.2013.845662

Tian, T., Olson, S., Whitacre, J. M., \& Harding, A. (2011). The origins of cancer robustness and evolvability. Integrative biology: quantitative biosciences from nano to macro, 3(1), 17-30. https://doi.org/10.1039/c0ib00046a

Toes, R. E., Hoeben, R. C., van der Voort, E. I., Ressing, M. E., van der Eb, A. J., Melief, C. J., \& Offringa, R. (1997). Protective anti-tumor immunity induced by vaccination with recombinant adenoviruses encoding multiple tumor-associated cytotoxic Tlymphocyte epitopes in a string-of-beads fashion. Proceedings of the National Academy of Sciences of the United States of America, 94(26), 14660-14665. https://doi.org/10.1073/pnas.94.26.14660

Tong, A. W., \& Stone, M. J. (2003). Prospects for CD40-directed experimental therapy of human cancer. Cancer gene therapy, 1 a(1), 1-13. https://doi.org/10.1038/sj.cgt.7700527

Tripodi, L., Vitale, M., Cerullo, V., \& Pastore, L. (2021). Oncolytic Adenoviruses for Cancer Therapy. International journal of molecular sciences, $22(5), 2517$. https://doi.org/10.3390/ijms22052517

Vivier, E., Tomasello, E., Baratin, M., Walzer, T., \& Ugolini, S. (2008). Functions of natural killer cells. Nature immunology, 9(5), 503-510. https://doi.org/10.1038/ni1582

Wang, Y., Xue, P., Cao, M., Yu, T., Lane, S. T., \& Zhao, H. (2021). Directed Evolution: Methodologies and Applications. Chemical reviews, 121(20), 12384-12444. https://doi.org/10.1021/acs.chemrev.1c00260

Wang, X., Zhong, L., \& Zhao, Y. (2021). Oncolytic adenovirus: A tool for reversing the tumor microenvironment and promoting cancer treatment (Review). Oncology reports, 45(4), 49. https://doi.org/10.3892/or.2021.8000

Wildner, O., Blaese, R. M., \& Morris, J. C. (1999). Therapy of colon cancer with oncolytic adenovirus is enhanced by the addition of herpes simplex virusthymidine kinase. Cancer research, 59(2), 410-413.

Wold, W. S. M. \& Horowitz, M. S. (2007). Adenoviruses. In D. M. Knipe \& P. M. Howley (Eds.), Fields Virology(pp. 2395-2436). Philadelphia, PA., Lippincott Williams \& Wilkins.

Woo, Y., Warner, S. G., Geha, R., Stanford, M. M., Decarolis, P., Rahman, M. M., Singer, S., McFadden, G., \& Fong, Y. (2021). The Oncolytic Activity of Myxoma Virus against Soft Tissue Sarcoma Is Mediated by the Overexpression of Ribonucleotide Reductase. Clinical Medicine Insights. Oncology, 15, 1179554921993069. https://doi.org/10.1177/1179554921993069

Xie, Z., Wroblewska, L., Prochazka, L., Weiss, R., \& Benenson, Y. (2011). Multi-input RNAi-based logic circuit for identification of specific cancer cells. Science (New York, N.Y.), 333(6047), 1307-1311.https://doi.org/10.1126/science.1205527

Yang, Y. F., Xue, S. Y., Lu, Z. Z., Xiao, F. J., Yin, Y., Zhang, Q. W., Wu, C. T., Wang, H., \& Wang, L. S. (2014). Antitumor effects of oncolytic adenovirus armed with PSA-IZ-CD40L fusion gene against prostate cancer. Gene therapy, 21(8), 723-731. https://doi.org/10.1038/gt.2014.46

Zhang, Q., \& Liu, F. (2020). Advances and potential pitfalls of oncolytic viruses expressing immunomodulatory transgene therapy for malignant gliomas. Cell death \& disease, 11(6), 485. https://doi.org/10.1038/s41419-020-2696-5

Zhang, M., Xian, H. C., Dai, L., Tang, Y. L., \& Liang, X. H. (2021). MicroRNAs: emerging driver of cancer perineural invasion. Cell \& bioscience, $11(1), 117$. https://doi.org/10.1186/s13578-021-00630-4 
Zhao, Y., Liu, Z., Li, L., Wu, J., Zhang, H., Zhang, H., Lei, T., \& Xu, B. (2021). Oncolytic Adenovirus: Prospects for Cancer Immunotherapy. Frontiers in microbiology, 12, 707290. https://doi.org/10.3389/fmicb.2021.707290

Zou, W., Wolchok, J. D., \& Chen, L. (2016). PD-L1 (B7-H1) and PD-1 pathway blockade for cancer therapy: Mechanisms, response biomarkers, and combinations. Science translational medicine, $8(328), 328 \mathrm{rv} 4$. https://doi.org/10.1126/scitranslmed.aad7118

\section{How to cite this article:}

Enekegho, L. O., \& Stuart, D. T. (2022). Smart Oncolytic Adenovirotherapy to Induce Killing of Cancer Cells and Elicit Antitumor Immunity. Eureka. 7(1). https://doi.org/10.29173/eureka28752. 